\title{
Seroprevalence and distribution of leptospiral serovars in livestock (cattle, goats, and sheep) in flood-prone Kelantan, Malaysia
}

\author{
Mohammad Sabri Abdul Rahman ${ }^{1}$, Siti Khairani Bejo ${ }^{1 凶}$, Zunita Zakaria $^{1}$, \\ Latiffah Hassan ${ }^{2}$, Mohd Azri Roslan ${ }^{1}$ \\ ${ }^{1}$ Department of Veterinary Pathology and Microbiology \\ ${ }^{2}$ Department of Veterinary Laboratory Diagnostics \\ Faculty of Veterinary Medicine, Universiti Putra Malaysia, 43400, Serdang, Selangor, Malaysia \\ skhairani@upm.edu.my
}

Received: July 2, $2020 \quad$ Accepted: December 16, 2020

\begin{abstract}
Introduction: Leptospirosis is a bacterial disease that affects both humans and animals, the occurrence of which increases markedly during and after heavy rainfall and flooding. The aim of this study was to determine the serological prevalence of leptospiral infection in livestock after a voluminous flood in 10 districts of the Malaysian state of Kelantan. Material and Methods: In December 2014, Kelantan was hit by an extensive flood. A total of 1,728 serum samples were collected from livestock from the state, comprised of 1,024 from cattle, 366 from goats and 338 from sheep, and they were tested using the microscopic agglutination test (MAT). Results: Altogether, 203 (11.75\%; 203/1728; 95\% CI: 10.20\%-13.30\%) of the tested sera were found to be positive serologically. Cattle had the highest prevalence of $14.16 \%$ (145/1024), while goats and sheep had $11.20 \%(41 / 366)$ and $5.03 \%$ (17/338) respectively. The most frequent serovars detected were Hardjo-bovis $(3.70 \% ; 64 / 1728)$, Hebdomadis $(2.08 \% ; 36 / 1728)$ and Pomona $(1.04 \% ; 18 / 1728)$. There was a statistically significant association $(\mathrm{P}<0.05)$ between livestock that were exposed to the flood and seropositivity. Conclusion: This study showed that flood is a risk factor that can play a role in the epidemiology of leptospiral infection in livestock.
\end{abstract}

Keywords: animals, flooding, leptospirosis, microscopic agglutination test, serovars.

\section{Introduction}

Leptospirosis is a common zoonotic disease occurring worldwide caused by pathogenic bacteria from the genus Leptospira. There are about 250 pathogenic and 60 saprophytic serovars known presently (1). Many species of wild and domestic animals may serve as carriers or maintenance hosts for Leptospira spp., including livestock, in which most leptospiral infections are subclinical. However, they may cause heavy economic losses due to abortion, stillbirth, and falling milk production (17). Humans may acquire infection through direct contact with infected animals or through indirect contact with them via water and soil contaminated with urine in which animals shed bacteria (22).

Floods have contributed to greater animal host exposure to leptospirosis agents that circulate in contaminated water. Consequently, the risk of water- borne diseases, including leptospirosis, has increased (26). During floods, many animal carriers or maintenance hosts of leptospirosis die and facilitate the spread of the disease to humans and animals indirectly through contact with water and soil contaminated by bacteraemic carcasses or urine of infected animals. After floods, leptospires might be present in puddles of water or moist soil and become a source of infection not only for animals (30). Heavy floods brought about by climate change are expected to predominantly affect tropical and sub-tropical regions. As a tropical region, Malaysia has had floodwater associated with its reported leptospirosis outbreaks (6), and the recurrence of outbreaks has established the country as an endemic area (16). The state of Kelantan on the east coast of the Malay Peninsular has the northeast monsoon as a climatic feature. This monsoon, which occurs from October to March, brings heavy rainfall resulting in frequent annual flooding (19). 
Various diagnostic tests have been described including microscopic examination, isolation of the microorganisms, and molecular and serological diagnosis (17). The serological method was used to diagnose leptospirosis in animals in field practice. The microscopic agglutination test (MAT) is the serological reference standard for leptospirosis diagnosis (18). Therefore, MAT was implemented in the present study to determine the seroprevalence of leptospiral infections in livestock after a prodigious flood in Kelantan. The frequency of individual infecting leptospiral serovars in livestock was also determined. The findings of this study are important for the purposes of monitoring and implementation of future preventive measures, especially during flood situations.

\section{Material and Methods}

Sample collection. Serum samples were collected from livestock (cattle, goats, and sheep) in 10 districts of Kelantan as shown in Table 1. The sampling period began in March and lasted until December 2015 following a surveillance programme conducted by the Department of Veterinary Services (DVS), the governmental organisation responsible for health, productivity, and welfare of animals in Malaysia. The sample collection overseen by the DVS complied with their standard requirements and procedural instructions. Livestock farms in Kelantan consist of smallholder, private, and government farms. Most of the animals are reared semi-intensively. All the sampled animals were apparently healthy and no clinical signs suggestive of leptospiral infection at the time of sampling were observed.

Microscopic agglutination test. The MAT performed was a modification of the method described in a previous study (13) in which animal sera were reacted with live antigen. After a two-hour-long incubation, the serum-antigen mixtures were examined microscopically for agglutination and the titres were determined. The seropositive titre for MAT was at dilution 1:100 (13). Results were considered positive when $50 \%$ or more agglutination was observed (4). The serum samples were tested for the presence of agglutinating antibodies against 19 leptospiral serovars as shown in Table 2 .

Statistical analysis. Serological prevalence was represented by means of descriptive statistics and was further analysed using Pearson's chi-squared test. This hypothesis test was carried out to determine any significant association between flooding and leptospiral infection in livestock and used IBM SPSS Statistics Version 23 (IBM, USA).

Table 1. Serum samples collected from livestock in 10 districts of Kelantan

\begin{tabular}{lllll}
\hline \multirow{2}{*}{ District } & Cattle & Goat & Sheep & Total \\
\hline Gua Musang & 246 & 74 & 79 & 399 \\
Kuala Krai & 21 & 49 & 11 & 81 \\
Jeli & 26 & 49 & 3 & 78 \\
Tanah Merah & 91 & 21 & 65 & 177 \\
Pasir Mas & 40 & 20 & - & 60 \\
Tumpat & 264 & - & 69 & 333 \\
Machang & 42 & 14 & 38 & 94 \\
Kota Bharu & 204 & 51 & 35 & 290 \\
Bachok & 47 & 16 & 21 & 84 \\
Pasir Puteh & 43 & 72 & 17 & 132 \\
\hline Total & 1024 & 366 & 338 & 1728 \\
\hline
\end{tabular}

Table 2. Leptospiral antigens for microscopic agglutination test (MAT)

\begin{tabular}{lll}
\hline Species & Serovar & Strain \\
\hline L. borgpetersenii & Hardjo-bovis & 117123 \\
L. interrogans & Hebdomadis & Hebdomadis \\
L. weilii & Celledoni & Celledoni \\
L. kmetyi & Malaysia & Bejo-ISO9 \\
L. interrogans & Pomona & Pomona \\
L. borgpetersenii & Tarassovi & Perepelitsin \\
L. interrogans & Pyrogenes & Salinem \\
L. interrogans & Australis & Ballico \\
L. kirschneri & Grippotyphosa & Moskva V \\
L. kirschneri & Cynopteri & $3522 \mathrm{C}$ \\
L. interrogans & Canicola & Hond Utrecht IV \\
L. interrogans & Lai & Lai \\
L. interrogans & Icterohaemorrhagiae & RGA \\
L. interrogans & Bataviae & Swart \\
L. borgpetersenii & Javanica & Veldrat Bataviae 46 \\
L. interrogans & Autumnalis & Akiyami A \\
L. borgpetersenii & Ballum & Mus 127 \\
L. interrogans & Djasiman & Djasiman \\
L. biflexa & Patoc & Patoc I \\
\hline
\end{tabular}




\section{Results}

Out of 1728 serum samples tested, 203 (11.75\%; 203/1728; 95\% CI: $10.20 \%-13.30 \%$ ) had a positive reaction in MAT with a titre range between 1:100 and $1: 1600$. Cattle had the highest prevalence of $14.16 \%$ (145/1024), while goats and sheep had 11.20\% (41/366) and $5.03 \%(17 / 338)$, respectively. The predominant serovars detected were Hardjo-bovis $(3.70 \%$; 64/1728), Hebdomadis $(2.08 \%$; 36/1728) and Pomona $(1.04 \%$; $18 / 1728)$, whereas all the sera tested were serologically negative for serovars Djasiman and Patoc, as shown in Fig. 1. Serovar Hardjo-bovis was the predominant serovar detected in cattle $(34.48 \% ; 50 / 145)$ and sheep $(47.06 \%$; $8 / 17)$, while the analogue in goats was Hebdomadis $(53.66 \% ; 22 / 41)$.

The districts of Gua Musang (4.17\%; 72/1728), Kota Bharu (1.74\%; 30/1728), Kuala Krai (1.22\%; $21 / 1728)$ and Tanah Merah $(1.10 \% ; 19 / 1728)$ showed higher distributions of leptospiral infection in livestock compared to the other six districts. Those districts showed distributions lower than $1.00 \%$, as shown in Fig. 2.

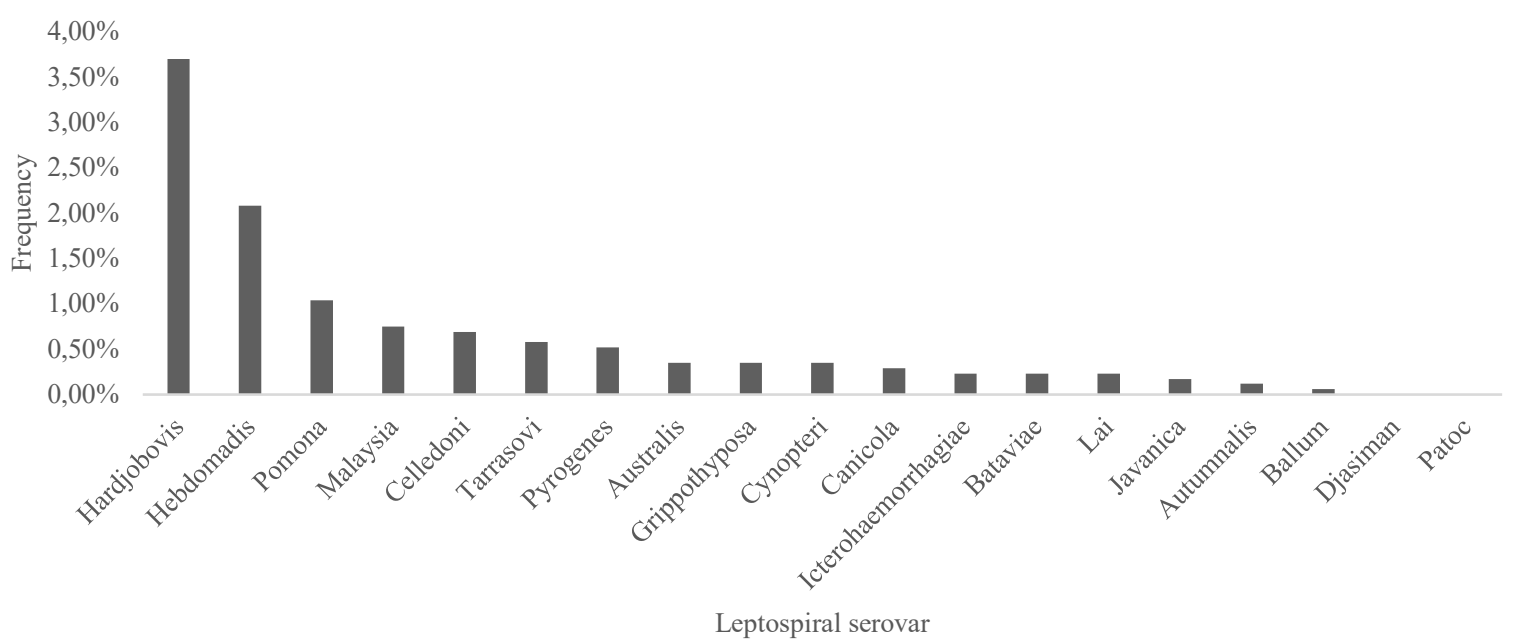

Fig. 1. Frequency of leptospiral serovars detected in livestock in Kelantan after an extensive flood in December 2014

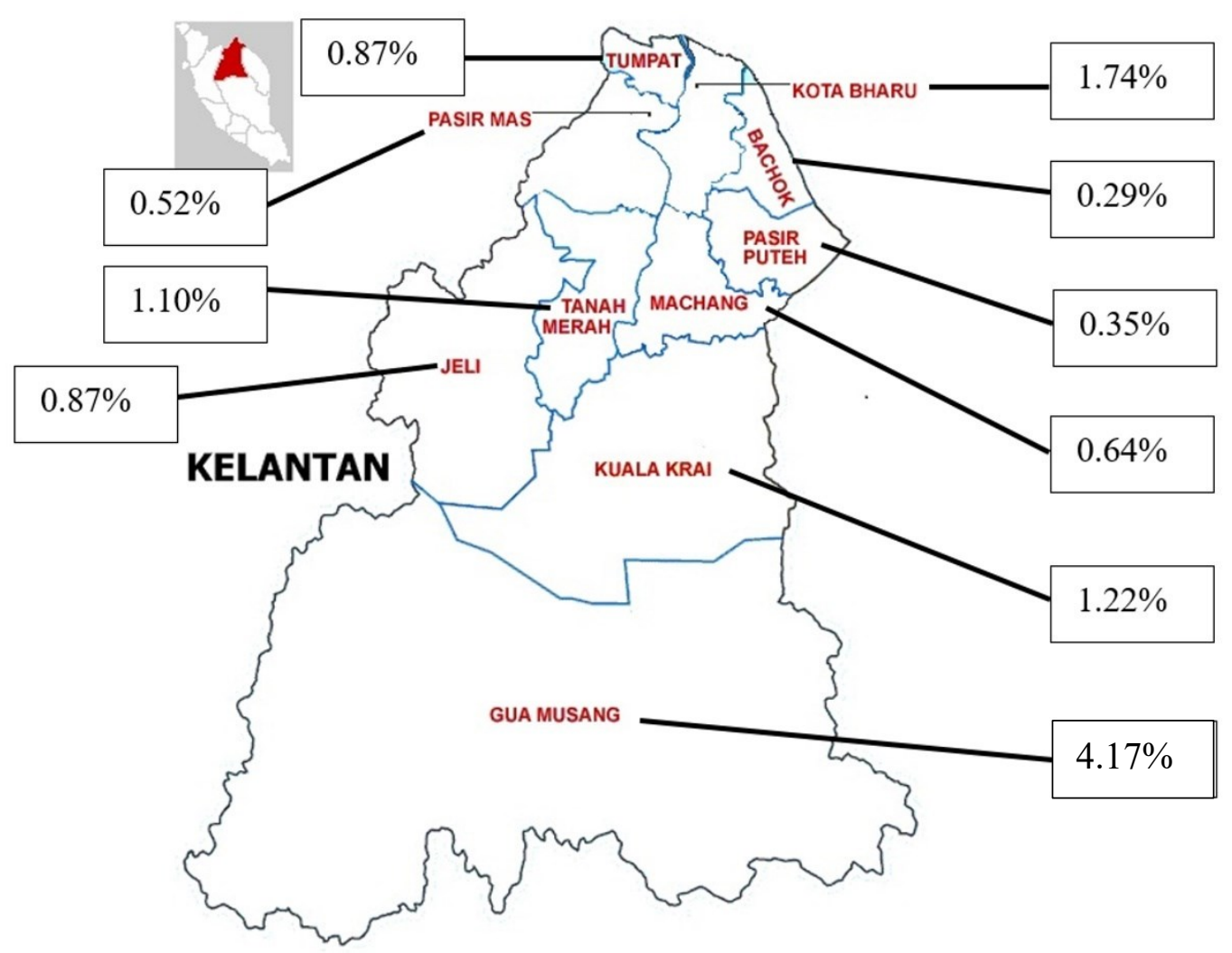

Fig. 2. Spatial distribution of leptospiral infection in livestock in Kelantan after an extensive flood in December 2014 
The State of Kelantan Center for Strategic Studies reported that all districts of Kelantan were affected by the flood in December 2014 except Bachok and Pasir Puteh (28). Therefore, only animals sampled from Bachok and Pasir Puteh were not exposed to the flood. The total number of livestock put at risk by the flood was 1,512, whilst the number of those never at risk was 216 . The MAT results showed that $12.70 \%$ (192/1512) of livestock affected by the flood were positive for leptospiral infection, whereas $5.09 \%(11 / 216)$ of livestock in areas that were unaffected by the flood were positive for antibodies. Pearson's chi-squared analysis revealed that there was a statistically significant association $(\mathrm{X} 2=10.55, \mathrm{p}=0.001162)$ between exposure to the flood and positivity for leptospiral infection, compared to the association between protection from the flood and positivity for infection. The analysis also revealed that the odds ratio between livestock exposed to the flood to the animals that were not exposed was 2.7 (95\% CI: 1.4-5.0).

\section{Discussion}

Leptospirosis may be caused by a variety of pathogenic leptospiral serovars and presents a threat after flooding. In the present study, the panel of antigens for MAT was comprised of the principal leptospiral serovars circulating in Malaysia. There were 38 leptospiral serovars that had been isolated from animals in the country (4). Due to the variety of infecting serovars, a wide range of clinical syndromes of leptospirosis can be expected. However, Levett (17) described most cases in livestock as occurring subclinically or showing mild clinical signs.

The overall serological prevalence of leptospiral infection in livestock in Kelantan after an extensive flood was $11.75 \% \quad(203 / 1728$; 95\% CI: $10.20 \%-$ $13.30 \%)$. This result was highly similar to a previous study which showed a seroprevalence of $12.86 \%$ (441/3430; 95\% CI: 11.70\%-14.00\%) (24). However, it was lower than those of previous studies conducted on the Malay Peninsular reporting 25.53\% (862/3377; 95\% CI: $24.10 \%-27.00 \%)(4)$ and $19.87 \%$ (30/151; 95\% CI: $13.89 \%-27.10 \%)$, the latter of these specifically for Kelantan (3). The present study's result was also lower than the seroprevalences found in other studies that were also conducted after floods in Indonesia, the Philippines and Japan of $22.73 \%$ (20/88; 95\% CI: $14.50 \%-32.90 \%)$ (11), 16.13\% (15/93; 95\% CI: 9.30\%-25.20\%) (2) and $23.89 \% \quad(97 / 406 ; 95 \%$ CI: $19.70 \%-28.00 \%)$ (17), respectively. The serological prevalence obtained in this study compared to previous studies was markedly different which could be due to the MAT positive cutoff titre and the target population.

In this study, cattle $(14.16 \% ; 145 / 1024)$ had the highest seroprevalence of leptospiral infection followed by goats $(11.20 \% ; 41 / 366)$ and sheep $(5.03 \% ; 17 / 338)$. This finding was consistent with the previous studies that showed leptospiral infection to be more frequent in cattle than in goats and sheep $(3,24)$. In Thailand, similar results were also reported where cattle had the highest seroprevalence of leptospiral infection out of cattle, buffalo, and pigs (8).

The panel of leptospiral serovars selected in this study contained the main serovars circulating in the country as found in previous studies $(4,24)$. The most frequent leptospiral serovars detected in livestock in Kelantan after the voluminous flood were Hardjo-bovis $(n=64)$, Hebdomadis $(n=36)$, and Pomona $(n=18)$. Testing for these leptospiral serovars is highly recommended in the future in leptospiral infection diagnosis, particularly in livestock. Serovar Hardjobovis is a common serovar maintained by cattle, while Hebdomadis has been reported to cause incidental infections in cattle. However, although serovar Pomona is common in sheep and goats, it is not in cattle (10).

Previous studies also noted a Hardjo-bovis predominance in cattle $(4,9,24)$. Most of the ruminants were apparently healthy despite the high frequency of serologically positive reactions for serovar Hardjobovis. It appears that this serovar is admirably adapted to and maintained in cattle and that the pathogenicity of this serovar in this host is low. There was a study in Malaysia suggesting that cattle are the serovar's maintenance host (15). Infected cattle become the source of Hardjo-bovis infection for other cattle, other animal species, and humans.

The predominant serovars detected in sheep and goats in this study were Hardjo-bovis and Hebdomadis, respectively, and this discovery was consistent with previous studies (24). In Iran, leptospirosis in sheep and goats occurred less commonly than in cattle (12), which is also an indication of the research presented here. Most of the goats and sheep in Kelantan are reared in raised sheds, which reduces the chance of contact with their urine and contaminated water and soil. A previous report stated that goats and sheep are usually let out to graze late in the day to prevent parasite infestation and that these animals prefer dry environments, which are not conducive to the survival and spread of leptospires (4).

Besides Hardjo-bovis, Hebdomadis and Pomona, serovars Tarrasovi, Australis, Grippotyphosa, Bataviae, Celledoni and Malaysia were also detected in this study. Tarrasovi, Australis and Grippotyphosa are common serovars that cause incidental leptospiral infections in cattle, goats, and sheep (10). However, serovars Bataviae, Celledoni and Malaysia are not common in these three animal species. Serovar Bataviae is commonly found in $\operatorname{dogs}(10,24)$ and rats $(5)$. This may suggest that the infected animals had previously been in contact with infected dogs, stray dogs, or rats. A similar situation is noted for serovar Celledoni, where this serovar is a rare leptospiral serovar for domestic animals but is common in humans and rats $(21,23)$. Contrastingly, serovar Malaysia was only isolated from soil in Johor (25) and leptospiral infection caused by it had never previously been reported. This may suggest 
that serovar Malaysia is commonly present in the Malaysian environment regardless of flood occurrence and could potentially infect animals and humans, but more studies should be carried out to prove this hypothesis.

In this study, the leptospiral infection rate in livestock that were exposed to the flood was higher than the rate in livestock that were not exposed. Floods have been consistently found to be a major risk factor for leptospirosis in other studies $(20,27)$. As a facilitator of leptospires transmission, flooding can increase the risk of exposure for animals and humans. It can spread the bacteria to previously uninfected farms, and even closed herds can become infected if water from other areas carries these microorganisms onto the farms. Pearson's chi-squared analysis revealed that there was a significant association between leptospiral infection in livestock and flooding. Livestock that were in jeopardy from floods were 2.7 times more likely to acquire leptospiral infection in comparison to livestock that were kept safe on dry ground. Previous reports suggested an association between canine and human leptospirosis on the one hand and flooded areas and flood events on the other which may support the finding in this study (29). The animals that were tested seropositive in the absence of the flood risk factor could have been exposed to other factors that enabled leptospiral infection, such as the presence of rodents, small mammals and other potential carriers on farms as well as the hygienic status of those farms, which were not the focus of this study. A study in Brazil reported that feeding on pasture, a weir and/or stream as the water source and absence of deworming procedures were also risk factors for leptospiral infection in livestock regardless of flood events taking place (7). The high distribution of leptospiral infection in livestock in an area could possibly be caused by continuous heavy rainfall and flooding in the affected area where animals had a high chance of being exposed to the contaminated water. Other factors such as the distribution of animals in an area, the stocking density of the animals (7), the movement of animals and the distance from farm to farm were also instrumental in spreading the disease; they could therefore affect the distribution of leptospiral infection in animals.

In conclusion, the overall serological prevalence of leptospiral infection across cattle, goats, and sheep is $11.75 \%$, cattle having the highest prevalence among the various species sampled. The most frequent leptospiral serovars detected in livestock in Kelantan after a flood were Hardjo-bovis, Hebdomadis, and Pomona. Therefore, these serovars are highly recommended to be tested for in the future for leptospiral infection diagnosis in livestock. Floods could facilitate leptospires transmission and distribution to susceptible livestock and present a threat to public health. This study proved that when floodwater encroached on livestock farms, animals raised there had a higher chance of becoming infected with leptospires than those raised where groundwater volume did not change. Treatment and quarantine of the infected livestock as control measures will reduce the risk of leptospiral infection in the human population, especially after flood. Additional precautions such as the wearing of proper personal protective equipment need to be taken at all times by farmers and veterinarians when handling the animals.

Conflict of Interests Statement: The authors declare that there is no conflict of interests regarding the publication of this article.

Financial Disclosure Statement: This study was supported by Universiti Putra Malaysia Research Grant GP-IPS/2016/9492600.

Animal Rights Statement: The sample collection was managed by the Department of Veterinary Services (DVS), Malaysia.

Acknowledgements: The authors wished to express their gratitude to the staff of the Bacteriology Laboratory, Faculty of Veterinary Medicine, Universiti Putra Malaysia and the Department of Veterinary Services (DVS), Malaysia for their technical assistance and significant contribution to this work.

\section{References}

1. Adler B., de la Pena-Moctezuma A.: Leptospira and leptospirosis. Vet Microbiol 2010, 140, 287-296.

2. Amilasan A.T., Ujiie M., Suzuki M.: Outbreak of Leptospirosis after flood, the Philippines, 2009. Emerg Infect Dis 2012, 18, 91-94.

3. Bahaman A.R., Ibrahim A.: A review of leptospirosis in Malaysia. Vet Res Commun 1988, 12, 179-189.

4. Bahaman A.R., Ibrahim A., Adam H.: Serological prevalence of leptospiral infection in domestic animals in West Malaysia. Epidemiol \& Infect 1987, 99, 379-392.

5. Benacer D., Mohd-Zain S.N., Sim S.Z., Mohd-Khalid M.K., Galloway R.L., Souris M., Thong K.L.: Determination of Leptospira borgpetersenii serovar Javanica and Leptospira interrogans serovar Bataviae as the persistent Leptospira serovars circulating in the urban rat populations in Peninsular Malaysia. Parasite Vector 2016, 9, 1-11.

6. Benacer D., Thong K.L., Min N.C., Verasahib K., Galloway R.L., Hartskeerl R.A., Souris M., Mohd-Zain S.N.: Epidemiology of human leptospirosis in Malaysia, 2004-2012. Acta Trop 2016, $157,162-168$.

7. Campos A.P., Miranda D., Rodrigues H., Carneiro-Lustosa M., Martins G., Mineiro A., Castro V., Azevedo S. S., Silva S.: Seroprevalence and risk factors for leptospirosis in cattle, sheep, and goats at consorted rearing from the State of Piauí, northeastern Brazil. Trop Anim Health Pro 2017, 49, 899-907.

8. Chadsuthi S., Bicout D.J., Wiratsudakul A., Suwancharoen D., Petkanchanapong W., Modchang C., Triampo W., Ratanakorn P., Chalvet-Monfray K.: Investigation on predominant Leptospira serovars and its distribution in humans and livestock in Thailand, 2010-2015. PLoS Negl Trop Dis 2017, 11, e0005228.

9. El-Jalii I.M.: Comparison between ELISA and the Microscopic Agglutination Test for the Diagnosis of Bovine Leptospirosis. Revue Élev. Méd. vét. Pays trop., 2008, 61, 73-75.

10. Ellis W.A.: Animal Leptospirosis. Curr Top Microbiol Immunol 2015, 387, 99-137. 
11. Fajriyah S.N., Udiyono A., Saraswati L.D.: Environmental and Risk Factors of Leptospirosis: A Spatial Analysis in Semarang City. IOP Conf Ser Earth Environ Sci 2017, 55, 1-10.

12. Hajikolaei M.R., Gorbanpour., Darioush G., Gholamreza A.: Serologic study on leptospiral infection in sheep in Ahvaz, Southern Iran. Iran J Vet Res 2007, 8, 333-336.

13. Hartskeerl R.A.: International course on laboratory methods for the diagnosis of leptospirosis; 19-23 April, 2004, Amsterdam, The Netherlands. FEMS Immunol Med Mic 2004, 40, page ii.

14. Kawaguchi L., Sengkeopraseuth B., Tsuyuoka R., Koizumi N., Akashi H., Vongphrachanh P., Watanabe H., Aoyama A.: Seroprevalence of leptospirosis and risk factor analysis in floodprone rural areas in Lao PDR. Am J Trop Med Hyg 2008, 78, 957-961.

15. Khairani-Bejo S., Bahaman A.R., Saad M.Z., Mutalib A.R.: The survival of Leptospira interrogans serovar Hardjo in the Malaysian environment. J Anim Vet Adv 2004, 3, 123-129.

16. Laras K., Bao C., Khanthong B., Thi N., James O., Sisouk T., Nguyen T., Kim H., Narain P., Ba H., Sam U., Sithat I., Douglas W., Beecham H., Andrew C.: The importance of Leptospirosis in Southeast Asia. Am J Trop Med Hyg 2002, 67, 278-286.

17. Levett P.N.: Leptospirosis: A forgotten zoonosis? Clin Immunol Rev 2004, 4, 435-448.

18. Lim V.K.: Leptospirosis: a re-emerging infection. Malays J Pathol 2011, 33, 1-5.

19. Malaysian Meteorological Department. "Weather phenomena". Archived from the original on 20 March 2008. Retrieved 15 June 2020. https://www.met.gov.my/?lang=en.

20. Mwachui M.A., Crump L., Hartskeerl R., Zinsstag J., Hattendorf J.: Environmental and Behavioural Determinants of Leptospirosis Transmission: A Systematic Review. PLoS Negl Trop Dis 2015, $9,1-15$.

21. Oliveira M.A., Leal E.A., Correia M.A., Serufo-Filho J.C., Dias R.S., Serufo J.C.: Human Leptospirosis: occurrence of serovars of
Leptospira spp. in the state of Minas Gerais, Brazil, from 2008 to 2012. Braz J Microbiol 2017, 48, 483-488.

22. Russ A.K., El-Jalii I., Bahaman A.R., Tuen A.A., Ismail G. Seroepidemiological study of leptospirosis among the indigenous communities living in the periphery of Crocker Range Park Sabah, Malaysia. ASEAN Review of Biodiversity and Environment Conservation (ARBEC) 2003, January-March, 1-5.

23. Samir A., Soliman R., El-Hariri M., Abdel-Moein K., Hatem M.E.: Leptospirosis in animals and human contacts in Egypt: broad range surveillance. Rev Soc Bras Med Tro 2015, 48, 272-277.

24. Samsi N.S., Zainol A., Darus A., Zainun Z., Wang C.S., Zainal Z., Hashim A.: Serodiagnosis of Leptospirosis in Domestic Animals and Humans. Malays J Vet Res 2013, 4, 21-26.

25. Slack A.T., Khairani-Bejo S., Symonds M.L., Dohnt M.F., Galloway R.L., Steigerwalt A.G., Bahaman A.R., Craig S., Harrower B.J., Smythe L.D.: Leptospira kmetyi sp. nov., isolated from an environmental source in Malaysia. Int J Syst Evol Microbiol 2009, 59, 705-708.

26. Smith J.K., Young M.M., Wilson K.L., Craig S.B.: Leptospirosis following a major flood in Central Queensland, Australia. Epidemiol Infect 2012, 141, 585-590.

27. Suwanpakdee S., Kaewkungwal J., White L.J., Asensio N., Ratanakorn P., Singhasivanon P., Day N.P., Pan-Ngum W.: Spatio-temporal patterns of leptospirosis in Thailand: is flooding a risk factor? Epidemiol Infect 2015, 143, 2106-2115.

28. Wan-Yussof W.N.: Flood in Kelantan in 2014: An Introspection Report from Centre for Strategic Studies, the State of Kelantan, Malaysia 2015

29. Ward M.P.: Seasonality of canine leptospirosis in the United States and Canada and its association with rainfall. Prev Vet Med 2002, 56, 203-213.

30. Wynwood S.J., Graham G.C., Weier S.L., Collet T.A., McKay D.B., Craig S.B.: Leptospirosis from water sources. Pathog Glob Health 2014, 108, 1-5. 